\title{
Contribution of Meteorological Conditions to Inter-annual Variations in Air Quality during the Past Decade in Eastern China
}

\author{
Haibo Ji', Min Shao ${ }^{2 *}$, Qin'geng Wang ${ }^{*}$ \\ ${ }^{1}$ State Key Laboratory of Pollution Control and Resources Reuse, School of the Environment, Nanjing University, Nanjing \\ 210023, China \\ ${ }^{2}$ School of Environment, Nanjing Normal University, Nanjing 210046, China
}

\begin{abstract}
During the past decade, air quality in China has undergone considerable variation, which is mostly attributable to anthropogenic emissions and meteorological conditions. The relative effects of meteorological conditions in eastern China were quantified using the Comprehensive Air Quality Model with Extensions (CAMx) for the period 2007-2016, and the year 2012 was chosen as the reference. In combination with observations of the air quality, the relative contributions of the two factors were identified. Six regions were selected according to their geolocations and regional climatic features. The results showed that meteorological conditions alone may have caused up to $10 \%$ of the variation in the mean annual air quality index. These conditions were generally favorable in coastal regions but unfavorable in inland ones, and they usually exerted a greater influence during winter. On average, anthropogenic emissions contributed approximately $70 \%$ of the change in $\mathrm{PM}_{10}$ concentration (relative to 2012) during the studied decade, but the contribution ratio varied significantly by region and year. Most regions exhibited lower anthropogenic ratios before 2012, indicating the major effects of anthropogenic emissions on air quality after this year. Furthermore, the considerable improvement in the air quality of these regions was mainly ascribed to reduced anthropogenic emissions. This study provides clear evidence that the air pollution control efforts that have been initiated in China since 2013, such as the Air Pollution Prevention and Control Action Plan (APPCAP), have succeeded in improving the air quality. However, attention must also be directed to the effects of meteorological conditions, which may cause severe pollution episodes even during low levels of emissions; thus, air pollution forecasting and appropriate emergency measures should be implemented in the future.
\end{abstract}

Keywords: Air quality; Eastern China; Air pollution control; WRF-CAMx; Meteorological effect.

\section{INTRODUCTION}

Since the late 1970 s, air quality in China has undergone long-term deterioration; however, it has improved significantly in recent years. In 2013, most cities in China experienced highly severe episodes of pollution. Zhang and Crooks (2014) reported that only approximately $1 \%$ of the 500 largest cities of China met the air quality standards recommended by the World Health Organization in 2012. In 2013, the annual concentration of fine particulate matter $\left(\mathrm{PM}_{2.5}\right)$ was $56.4 \mathrm{\mu g} \mathrm{m}^{-3}$ in 113 major cities, and only $14.2 \%$ of these cities met the new ambient air quality standard set for China (35 $\mu \mathrm{g} \mathrm{m}^{-3}$ for $\mathrm{PM}_{2.5}$; GB3095-2012). In response to this situation, the Chinese government has invested considerable

\footnotetext{
* Corresponding author.

E-mail address: mshao@masonlive.gmu.edu (M. Shao); wangqg@nju.edu.cn (Q. Wang)
}

efforts at different levels to combat air pollution. In particular, the Air Pollution Prevention and Control Action Plan (APPCAP) was launched in 2013 by the central government and subsequently adopted by every local government; it entails highly stringent rules and detailed objectives. Since the launch of APPCAP, evidence has shown that air quality in most cities in China has improved significantly. For example, the annual concentration of $\mathrm{PM}_{2.5}$ in Beijing decreased from $89 \mu \mathrm{g} \mathrm{m}^{-3}$ in 2013 to $73 \mu \mathrm{g} \mathrm{m}^{-3}$ in 2017 , and that in Nanjing decreased from $78 \mu \mathrm{g} \mathrm{m}^{-3}$ to $48 \mu \mathrm{g} \mathrm{m}^{-3}$ during the same period according to the China Statistical Yearbook. Air pollution has been reported to be mainly caused by a combination of high levels of emissions and unfavorable meteorological conditions (Jacob and Winner, 2009; Tai et al., 2010). Hence, whenever a notable improvement in air quality is reported in China, particularly the significant improvements in recent years, many researchers are interested in the contribution of meteorological conditions to improving air quality. These investigations are useful for evaluating the effectiveness of pollution control measures and improving 
them to achieve superior results in the future.

Meteorological conditions may exert long- and shortterm effects on air quality (Goncalves et al., 2009; Jacob and Winner, 2009; Yang et al., 2015; Mao et al., 2016). On a long-term scale, climate change may statistically affect the air quality in terms of perturbations in wind speed, precipitation, frequency of cyclones, heat waves, etc. (Hou and $\mathrm{Wu}, 2016)$. On a short-term scale, synoptic weather systems have more obvious and instantaneous effects on air pollution episodes. The transportation, diffusion, deposition, and chemical reactions of air pollutants are strongly affected by many factors of local weather systems such as wind gust, wind direction, convective storms, mixing height, cloudiness, etc. (Jacob and Winner, 2009). Notably, the vast extent of China as well as the diversity in features of the terrain result in complex regional climate and weather systems in different regions (Fu et al., 2008; Zhang and Zhou, 2015) and increase the complexity of the effects of meteorological conditions on air quality.

Many studies have focused on the relationship between meteorological factors and physical and chemical processes of air pollution. Local meteorological factors and synopticscale atmospheric circulations, such as the land-sea breeze, play an important role in either the formation or diffusion (transportation) of air pollutants, particularly in coastal cities (Flocas et al., 2009; Buchholz et al., 2010). Goncalves et al. (2009) found that the transportation of $\mathrm{NO}_{x}$ emissions is the major cause of $\mathrm{O}_{3}$ photochemical formation in downwind regions. Chen et al. (2008) and Yang et al. (2009) found that better air qualities are more associated with synoptic-scale high-pressure gradients; however, this conclusion was based on limited observations. Numerical models, which can provide additional details with high temporal and spatial resolutions, can enhance our understanding of the effects of meteorological factors on air quality. Jeong and Park (2013) investigated relationships between meteorological variables and air pollution in East Asia by using the global three-dimensional Goddard Earth Observing System and chemical transport model (GEOS-Chem) and reported that meteorological variables accounted for $30 \%$ of the increase in ozone $\left(\mathrm{O}_{3}\right)$ concentration. Mu and Liao (2014) investigated the interannual variations in surface aerosols caused by changes in meteorological conditions and found that northern China has a larger absolute percentage departure from mean (annual mean: 14\%) than southern China (annual mean: 10\%). Their team further analyzed the meteorological contribution to changes in $\mathrm{PM}_{2.5}$ concentrations based on a stepwise multiple linear regression model and reported that meteorological conditions accounted for approximately $12 \%$ of the reduction in $\mathrm{PM}_{2.5}$ concentrations across China (Zhai et al., 2019). Furthermore, Yang et al. (2015) and Mao et al. (2016) quantified the decadal trend and interannual variation in air pollution outflow from East Asia by using the GEOS-Chem system for the years 1986-2006; the results showed that the interannual variation in air pollution outflow was dominated by variations in meteorological parameters. Wang et al. (2019) quantified the effects of meteorological conditions on $\mathrm{PM}_{2.5}$ concentrations in 31 provincial capitals in China by using 3year model simulation results associated with observations.
Although the aforementioned studies have revealed the relationships between meteorological parameters and air quality, the relative effects of the meteorological conditions on interannual and seasonal variations in air quality, compared with those of anthropogenic emissions, have not been adequately investigated and determined, particularly in typical cities in China over the past 10 years, over which time trends in air quality have changed remarkably.

In this study, we assessed the relative contributions of meteorological conditions and anthropogenic emissions to both interannual and seasonal variations in air quality during the past 10 years over eastern China. A total of 22 provincial cities were selected and classified into six groups to represent different types of meteorological features in China. The advanced core of the Weather Research and Forecasting model (WRF-ARW) and the Comprehensive Air Quality Model with Extensions (CAMx) were applied for simulating air quality, with a fixed emission inventory. Combined with the observations of air quality, the relative effects of meteorological and anthropogenic factors affecting interannual and seasonal variations in air quality were identified. Additionally, implications for policy formulation are discussed. A brief introduction to the models and the experimental design are provided in Section 2. Validation of the model performance is described in Section 3. Simulated interannual and seasonal variations of air pollutants are presented in Section 4. The relative effects of meteorological factors and anthropogenic emissions are discussed in Section 5. The major findings and discussion thereof are summarized in Section 6.

\section{STUDY DOMAIN, MODELS, AND DATA}

As shown in Fig. 1, the study domain covered eastern China. The selected cities were classified into six groups (Table 1) by considering different meteorological characteristics and urban agglomerations, which are marked in Fig. 1. The Beijing-Tianjin-Hebei (BTH) urban agglomeration, the Yangtze River Delta (YRD) urban agglomeration, and the Pearl River Delta (PRD) urban agglomeration are the three biggest economically integrated regions in China, and they all are located in the coastal region. The northeastern region (NE) is usually colder and dryer than most other regions, and the western inland (WI) and the central inland (CI) regions usually exhibit larger diurnal meteorological variations than the coastal regions.

The widely used mesoscale meteorological model WRFARW version 3.7.1 (Skamarock et al., 2008; Wang et al., 2011) was used to simulate meteorological conditions in this study. The major physics schemes are the WRF SingleMoment 3-class scheme for microphysics, Rapid Radiative Transfer Model scheme for longwave radiation, Goddard shortwave scheme for shortwave radiation, Noah Land Surface Model for land surface process, Yonsei University scheme for the planetary boundary layer, and Grell-Devenyi ensemble scheme for cumulus parameterization. The model domain was designed using a horizontal resolution of $27 \mathrm{~km}$ $\times 27 \mathrm{~km}$ and 30 vertical levels from the surface to $50 \mathrm{mb}$.

The CAMx (v6.40; Ramboll ENVIRON, 2016) is an 


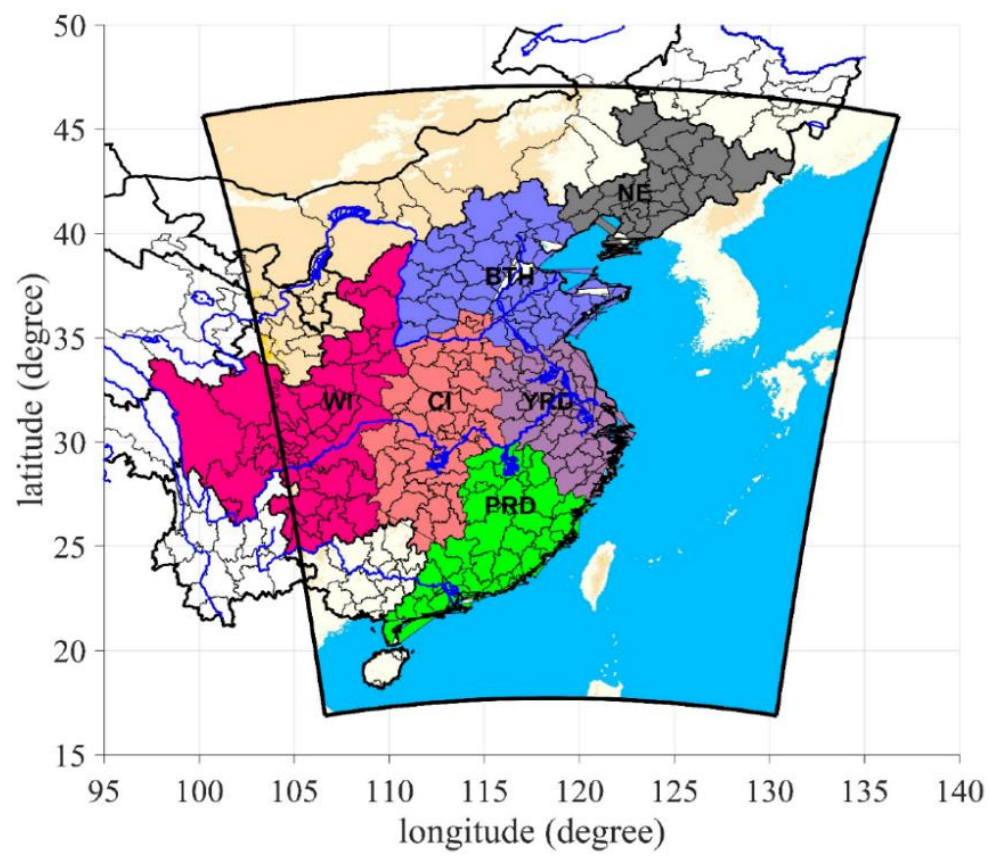

Fig. 1. Model domain for WRF and CAMx. Shaded areas are regions classified in this study. BTH for the Beijing-TianjinHebei, $Y R D$ for the Yangtze River Delta, $N E$ for the northeast, $P R D$ for the Pearl River Delta, $C I$ for the central inland, and $W I$ for the western inland.

Table 1. List of selected cities in typical regions.

\begin{tabular}{ll}
\hline Region & City List \\
\hline Beijing-Tianjin-Hebei (BTH) & 1 Beijing, 2 Tianjin, 3 Taiyuan, 4 Shijiazhuang, 5 Jinan, 6 Qingdao \\
Yangtze River Delta (YRD) & 7 Shanghai, 8 Nanjing, 9 Hangzhou, 10 Hefei \\
Pearl River Delta (PRD) & 11 Guangzhou, 12 Fuzhou, 13 Nanchang \\
Northeast (NE) & 14 Changchun, 15 Dalian, 16 Shenyang \\
Central inland (CI) & 17 Zhengzhou, 18 Wuhan, 19 Changsha \\
Western inland (WI) & 20 Xi'an, 21 Chongqing, 22 Guiyang \\
\hline
\end{tabular}

Eulerian chemical transport model that has been widely used in air quality simulations for various purposes. The model is driven by WRF outputs, and the 2005 version of the Carbon Bond chemical mechanism (CB05; Yarwood et al., 2005) was selected as the chemical mechanism. The secondary organic aerosol partitioning (SOAPv1.1) scheme was used for organic gas-aerosol partitioning and oxidation. The domain overlapped with the WRF domain, and both had identical vertical levels. Six grid points at each horizontal boundary were used as buffer areas for the CAMx domain.

The 6-hour NCEP Final (FNL) Operational Global Analysis data, with a resolution of $1^{\circ} \times 1^{\circ}$, were used as the initial atmospheric and lateral boundary conditions for the WRF-ARW model. The 2012 version of Multi-resolution Emission Inventory for China (MEIC; Zhang et al., 2009; Li et al., 2014; Zheng et al., 2014; Liu et al., 2015) was used in this study. The MEIC, which was developed by Tsinghua University, consists of six categories of anthropogenic emission sources and 10 species of air pollutants. Biogenic emissions were assumed to exert relatively small effects and were not considered in this study. The annual concentrations of the air pollutants were obtained from the Ministry of Ecology and Environment of China. Data are available at the real time release platform of national air quality: http://106.37.208.233:20035/. To validate performance of the models, hourly concentrations of six regular air pollutants $\left(\mathrm{SO}_{2}, \mathrm{NO}_{2}, \mathrm{CO}, \mathrm{O}_{3}, \mathrm{PM}_{10}\right.$, and $\left.\mathrm{PM}_{2.5}\right)$ and hourly near-surface meteorological observations in Nanjing in 2013 were collected. However, observations of $\mathrm{PM}_{2.5}$ and $\mathrm{O}_{3}$ were only available starting from 2013 in Nanjing. Hence, the emission inventory was updated to 2013 over the YRD region according to a deep investigation of emission sources, which was performed for air quality management in 2014 during the Youth Olympic Games hosted in Nanjing.

To determine the effect of meteorological factors on air quality, emissions were maintained consistently throughout the study period. Factors such as the simulated concentrations of air pollutants in each of the selected cities were obtained for the period of 2007-2016. January, April, July, and October were selected as representative months for winter, spring, summer, and autumn, respectively. Based on the simulated concentrations of the six pollutants, daily air quality indexes (AQIs) were calculated according to the method defined in the Technical Regulation on Ambient Air Quality Index (HJ633-2012).

To quantify the variations in air quality, in terms of either 
concentration or AQI, the relative change (RC) is defined using Eq. (1), as suggested by Mu and Liao (2014):

$$
R C=\frac{C_{i}-C_{r e f}}{C_{r e f}} \times 100 \%
$$

where $C_{i}$ is the air pollutant concentration or index value in year $i$, and $C_{\text {ref }}$ is the value in the reference year 2012 . Therefore, RCs indicate variations in a certain year relative to the value in the reference year.

\section{VALIDATION OF MODEL PERFORMANCE}

Hourly meteorological and air quality observations in the year 2013 in Nanjing were compared with simulated results. Fig. 2 shows the comparison between the observed and simulated temperatures at a height of $2 \mathrm{~m}$ and a wind speed at a height of $10 \mathrm{~m}$. The correlation coefficients between the observed and the simulated temperature and wind speed were 0.98 and 0.77 , respectively, and both were greater than the $90 \%$ confidence level. For temperature, the root mean square error (RMSE) and bias were $2.27 \mathrm{~K}$ and $0.5 \mathrm{~K}$, respectively. For wind speed, the RMSE and bias were $1.58 \mathrm{~m} \mathrm{~s}^{-1}$ and $1.12 \mathrm{~m} \mathrm{~s}^{-1}$, respectively. The results indicated that the WRF model satisfactorily reproduced the diurnal and seasonal variations in meteorological factors and can provide reliable meteorological fields for air pollution modeling.

Fig. 3 presents comparisons between the observed and simulated near-surface hourly average concentrations of $\mathrm{SO}_{2}, \mathrm{NO}_{2}, \mathrm{PM}_{10}, \mathrm{PM}_{2.5}, \mathrm{CO}$, and daily maximum 8-h $\mathrm{O}_{3}$. For $\mathrm{SO}_{2}, \mathrm{NO}_{2}, \mathrm{PM}_{10}, \mathrm{PM}_{2.5}, \mathrm{CO}$, and $\mathrm{O}_{3}$, the correlation coefficients between the observed and the simulated values were $0.50,0.70,0.66,0.77,0.72$, and 0.74 , respectively, and the RMSE/biases were 31.26/ 0, 24.27/5.28, 66.24/-13.63, $34.76 /-1.59,0.52 /-0.04$, and 43/ 0 $\mu \mathrm{g} \mathrm{m}^{-3}$, respectively. The CAMx slightly overestimated the $\mathrm{NO}_{2}$ concentration in winter and early spring, which is possibly related to the underestimation of ozone in corresponding seasons. The CAMx also underestimated the PMs, which may have been a result of neglecting biogenic emissions. Nevertheless, the results indicated that the CAMx can reasonably reproduce the diurnal and seasonal variations in air quality with an acceptable uncertainty.

\section{METEOROLOGICAL EFFECTS ON ANNUAL AND SEASONAL AIR QUALITY}

With fixed emissions, interannual variations in the simulated air quality reflect only the effects of meteorological conditions. Fig. 4 shows the simulated annual mean AQIs and RCs compared with the reference year and linear trends in the six regions in the period of 2007-2016. The effects of meteorological conditions varied by region. Generally, in NE, YRD, and PRD, decreasing linear trends were observed, which indicated that the meteorological conditions in these regions became favorable from 2007 to 2016. By contrast, in BTH, WI, and CI, increasing trends were observed, which indicated unfavorable meteorological conditions.

Unlike long-term linear trends, for some specific periods, the trends may be different. For example, the AQIs in most of the regions increased from 2011 to 2013, which indicated negative effects of meteorological factors on air quality. This may be an important reason for the extremely heavy air pollution that occurred across China in 2013. By contrast, the AQIs decreased in all six regions from 2014 to 2016, which indicates positive meteorological effects on air quality. This finding suggests that in addition to the efforts to reduce anthropogenic emissions, meteorological conditions also contributed notably to the considerable improvement in air quality in recent years.

The RCs in AQIs in Fig. 4 indicate the contribution of meteorological conditions to the overall effects (relative to the reference year), showing that the overall RCs may be as large as $10 \%$, but RCs may vary notably with region. The ranges of RCs are $-3 \%$ to $9 \%$ in NE, $-6.7 \%$ to $7.2 \%$ in $\mathrm{BTH}$, $-4.3 \%$ to $6.8 \%$ in YRD, $-9.6 \%$ to $8.1 \%$ in PRD, $-7.8 \%$ to $2.2 \%$ in $\mathrm{CI}$, and -0.3 to $-7.2 \%$ in WI.

Compared with the reference year 2012, during the period of 2007-2016, meteorological conditions were mostly unfavorable in NE; generally favorable in BTH, WI, and CI; and considerably fluctuant in YRD and PRD. Notably, the meteorological conditions in the years 2013 and 2014 were (a) Temperature at 2-m height

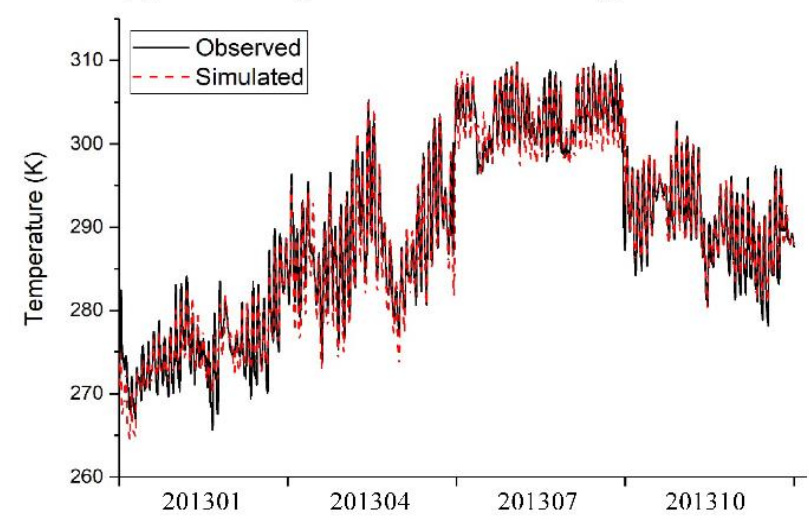

\section{(b) Wind Speed at $10-\mathrm{m}$ height}

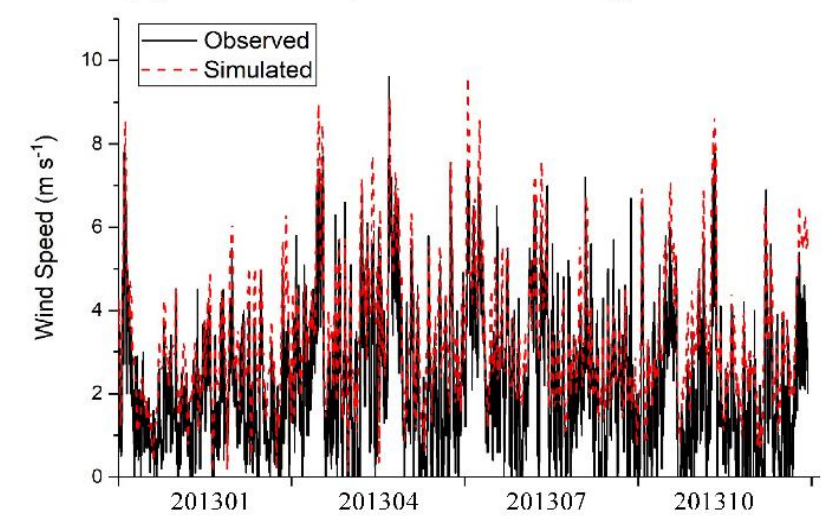

Fig. 2. Comparison of the observed and simulated for (a) temperature at a 2-m height and (b) wind speed at a 10-m height. 
(a)
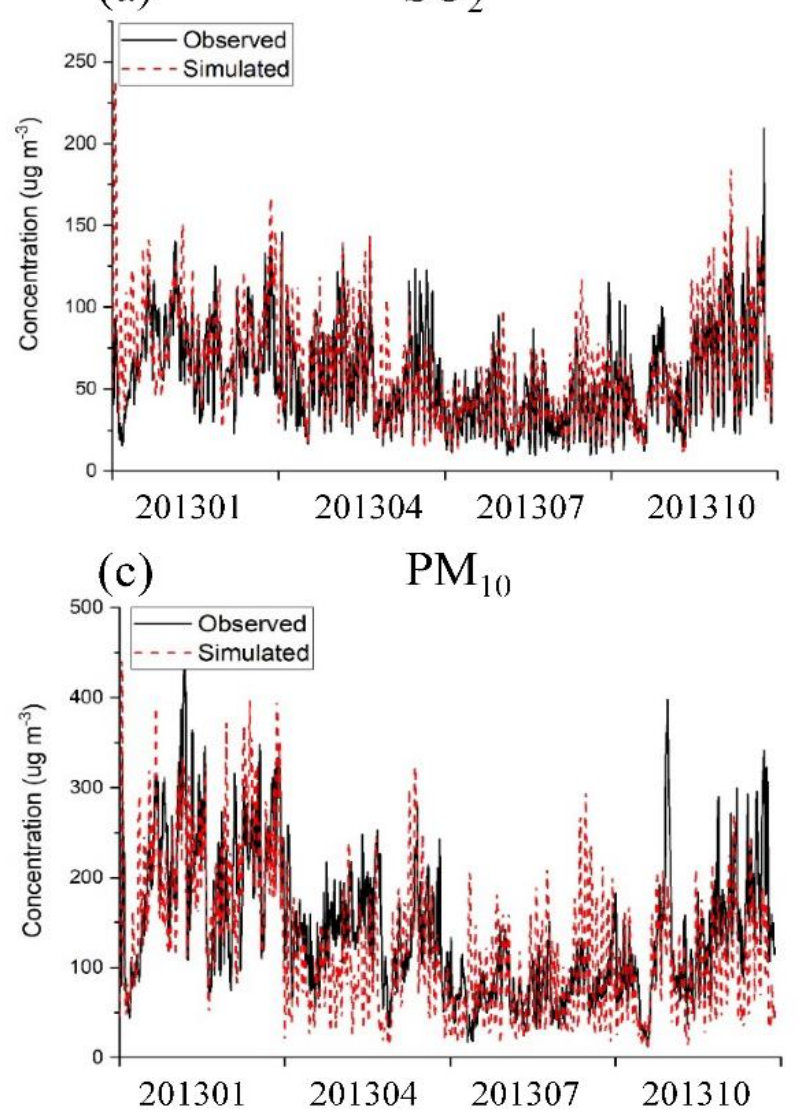

(e)

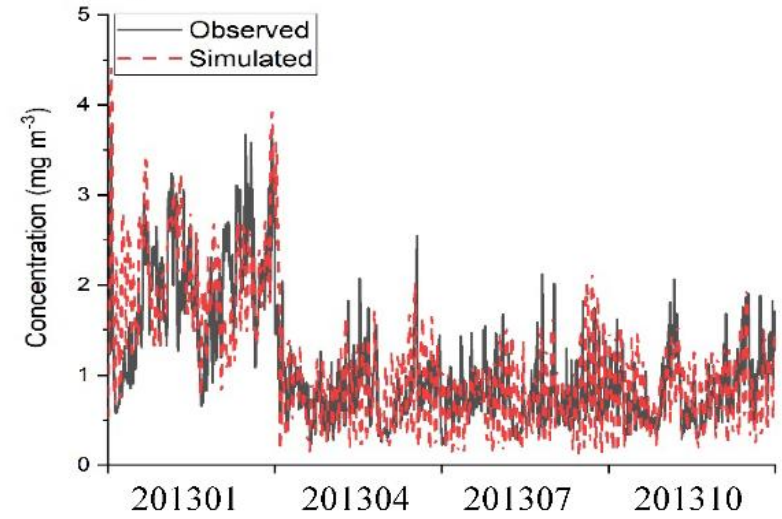

(b)
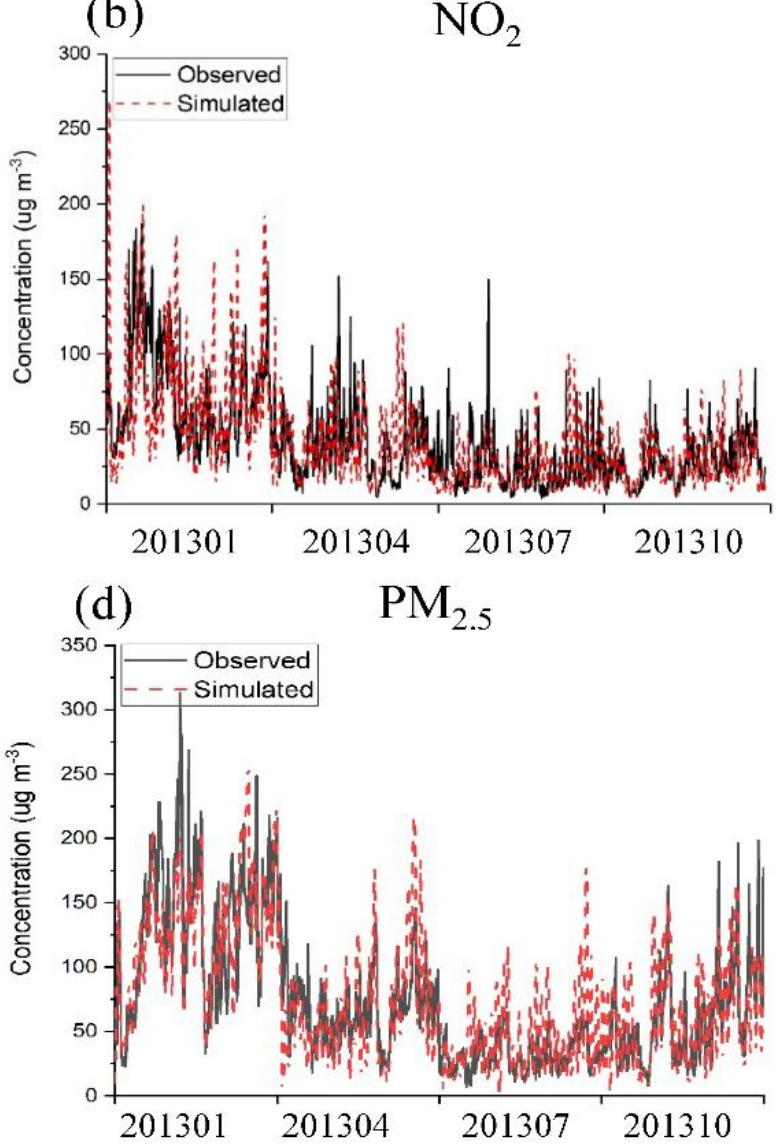

(f)

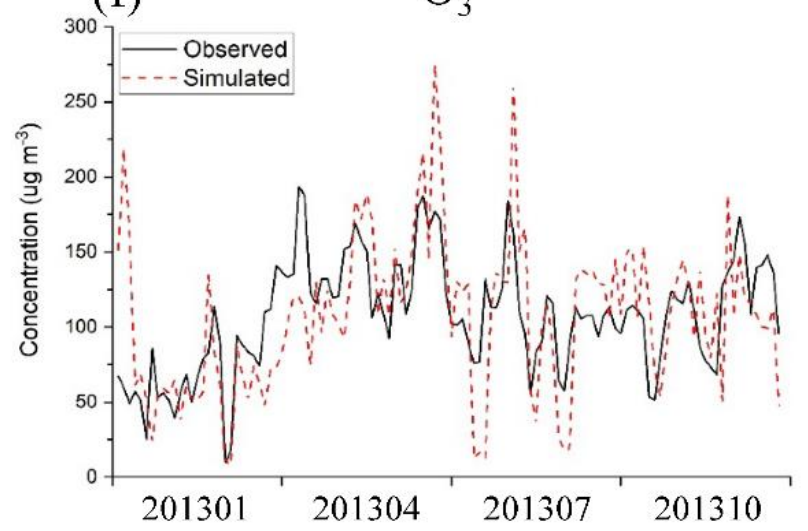

Fig. 3. Comparison of the observed and simulated concentrations of (a) hourly $\mathrm{SO}_{2}$, (b) hourly $\mathrm{NO}_{2}$, (c) hourly $\mathrm{PM}_{10}$, and (d) daily maximum $8-\mathrm{h} \mathrm{O}_{3}$.

unfavorable for almost all the regions, particularly BTH. Detailed analysis showed that two-thirds of the selected cities in BTH, NE, and WI regions experienced extremely unfavorable meteorological conditions in 2013 (data not shown). These findings are consistent with those of multiple studies that have reported extreme haze over northern China in winter 2013 (e.g., Ji et al., 2014; Tao et al., 2014).

Meteorological conditions usually have extremely different seasonal effects on air quality in different regions. In typical seasonal atmospheric cycles, such as the Asian Monsoon, with influencing regions moving northward from spring to autumn and then back to the tropics from autumn to spring (Huang et al., 2012). Regions such as PRD, CI, and YRD are all significantly affected by the Asian Monsoon. NE and BTH regions are northern regions strongly affected by cold fronts. WI is affected by the Tibetan Plateau. The RCs in the seasonal mean AQI in different regions are plotted in Fig. 5 and based on the simulated results obtained with fixed emissions.

The effects of meteorological conditions on air quality differed considerably with season and region. Winter usually had greater effects in most regions. Furthermore, in YRD 
(a) $\mathrm{NE}$

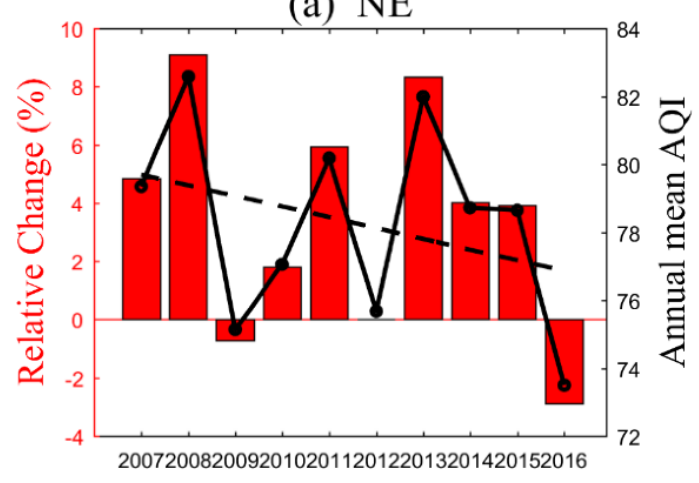

(c) YRD

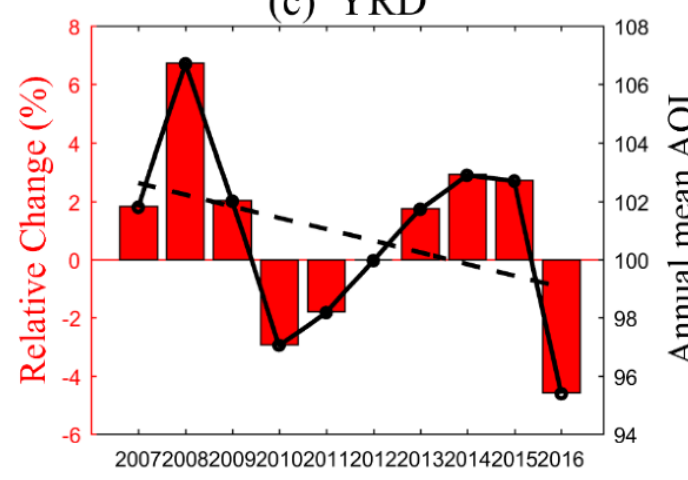

(e) $\mathrm{CI}$

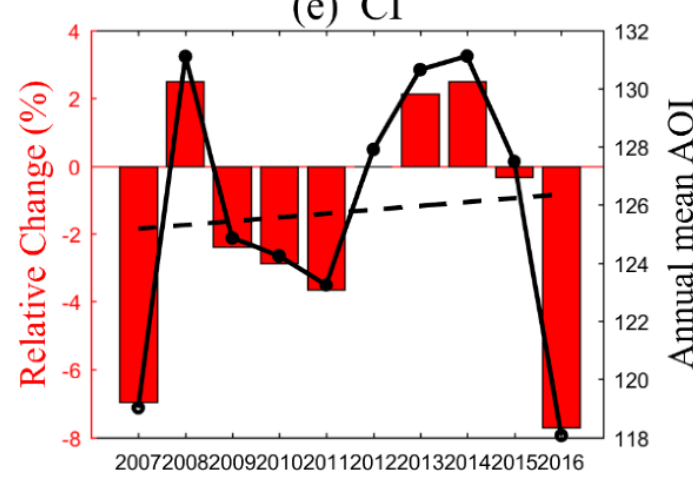

(b) $\mathrm{BTH}$

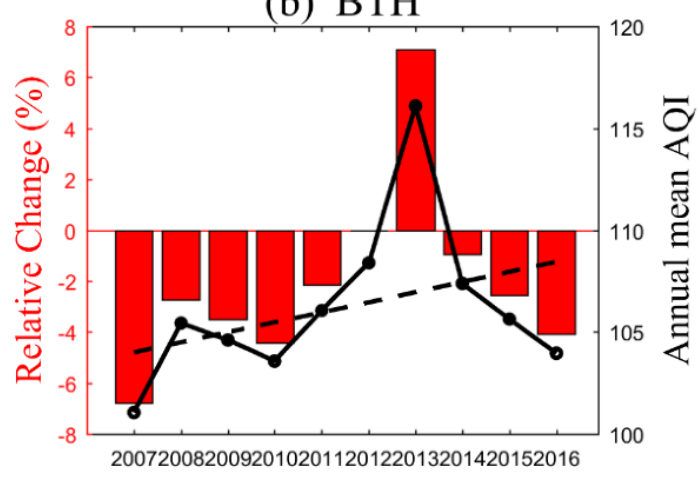

(d) PRD

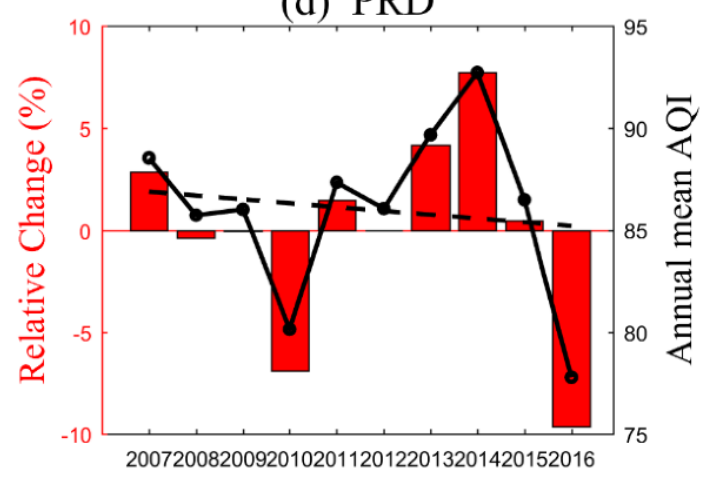

(f) WI

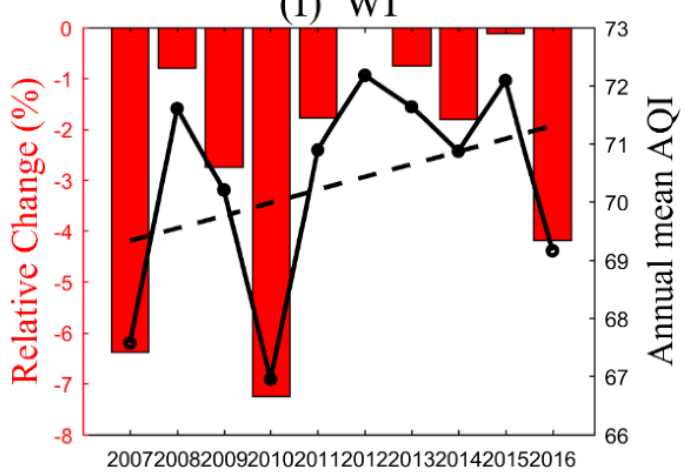

Fig. 4. The simulated annual mean AQIs (black solid lines) accompanied by the linear trends (black dashed lines) and relative changes (RCs) compared with the reference year 2012 (red bars) in six regions: (a) NE, (b) BTH, (c) YRD, (d) PRD, (e) CI, and (f) WI.

and PRD, winter tended to exhibit higher AQIs (positive $\mathrm{RCs}$ ), especially in YRD, which indicated deterioration in air quality. However, in other regions, winter tended to exhibit decreased AQIs (negative RCs), which implied improved air quality. Summer and autumn also showed considerable variation in AQI. In particular, summer RCs in NE, PRD, $\mathrm{CI}$, and WI were generally positive and clearly larger than those in BTH and YRD. However, the autumn RCs in PRD, YRD, and CI were generally negative and larger in magnitude than in other regions. Winter meteorological conditions became favorable from 2013 to 2016 in most of the regions, which should have contributed substantially to the improvement in air quality.

\section{DISTINCTION BETWEEN METEOROLOGICAL AND ANTHROPOGENIC EFFECTS ON PM PM $_{10}$}

Air quality is a combined result of meteorological conditions and anthropogenic emissions. Distinguishing the relative effects of the two contributors is necessary to understand variations in air quality as well as the effectiveness of pollution control efforts. In general, relative effects are different for different pollutants. In this study, due to the availability of observational data, relative effects of the two contributors in $\mathrm{PM}_{10}$ concentration were distinguished. Therefore, hourly concentrations of $\mathrm{PM}_{10}$ with a fixed emission inventory for the reference year 2012 were extracted from the simulations 
(a) $\mathrm{NE}$

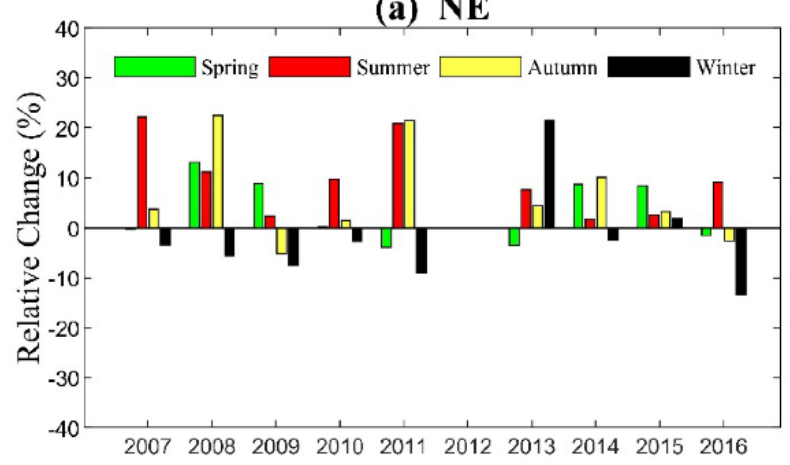

(c) YRD

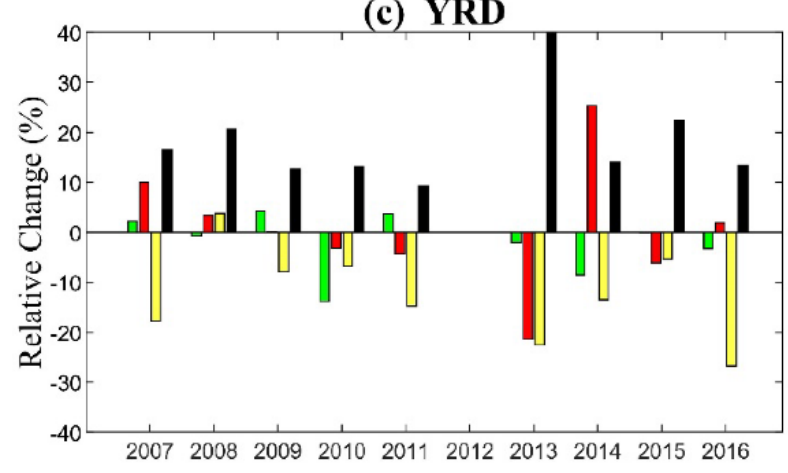

(e) $\mathrm{CI}$

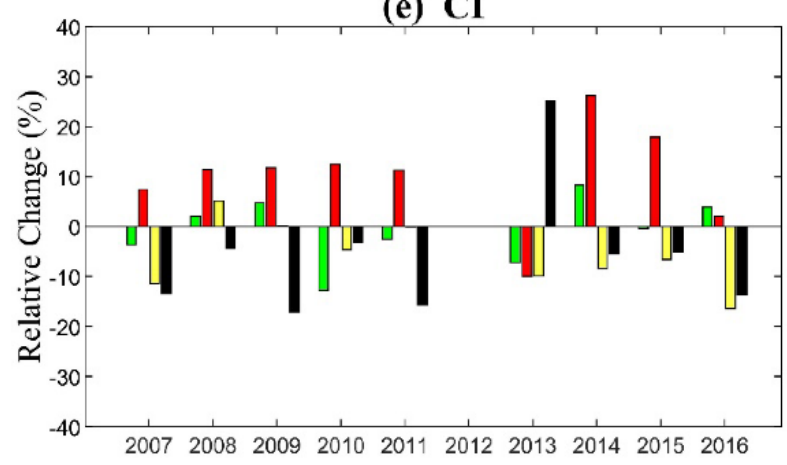

(b) BTH

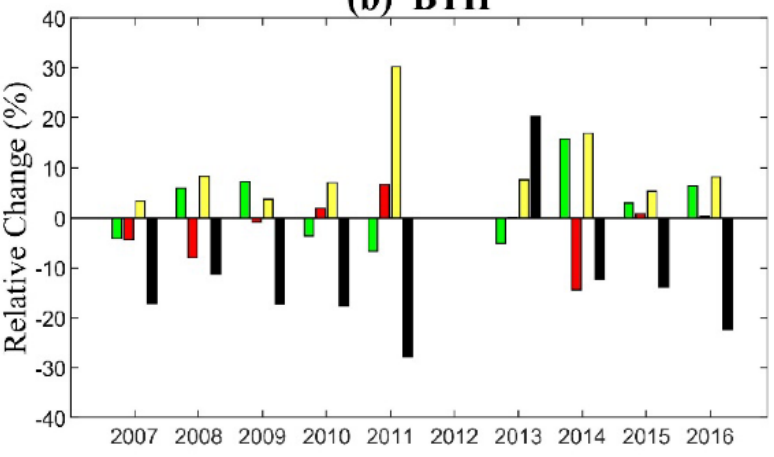

(d) PRD

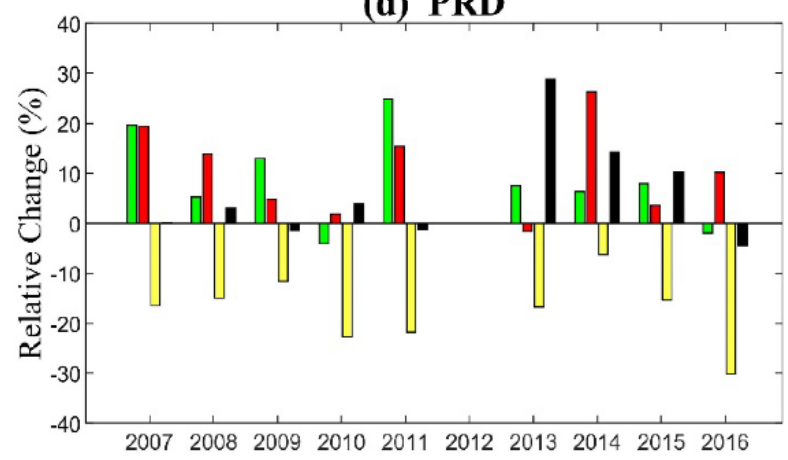

(f) WI

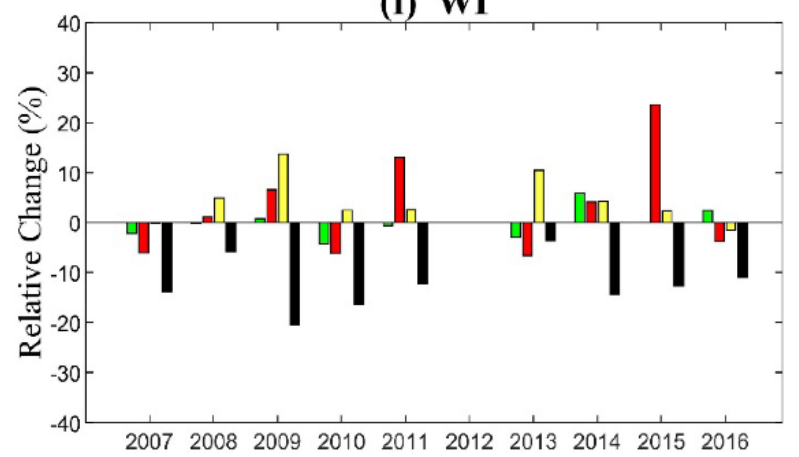

Fig. 5. RCs in seasonal mean AQI against the reference year 2012 in (a) NE, (b) BTH, (c) YRD, (d) PRD, (e) CI, and (f) WI.

of 2007-2016. Theoretically, the simulated and observed results should match in the reference year. Therefore, the simulated concentrations were adjusted to a level at which the simulated values in 2012 were equal to the observed. Annual RCs in the simulated and observed $\mathrm{PM}_{10}$ from 2007 to 2016 were calculated and are plotted in Fig. 6. The differences between the observed and simulated results indicate the effects of anthropogenic emissions. The RCs in simulated $\mathrm{PM}_{10}$ were generally considerably smaller than those of the observed $\mathrm{PM}_{10}$ for most of the years, which indicated that anthropogenic emissions dominated the RCs. Actually, as much as $88 \%$ of the RCs could be attributed to anthropogenic effects, with only $13 \%$ attributed to the meteorological effects. The RCs in simulated $\mathrm{PM}_{10}$ in different regions were as follows: $-9.7 \%$ to $7.1 \%$ in NE, $-9.8 \%$ to $8.7 \%$ in BTH, $-8.4 \%$ to $10.25 \%$ in YRD, $-8 \%$ to $1.9 \%$ in
PRD, $-13 \%$ to $4.2 \%$ in CI, and $-4.1 \%$ to $0 \%$ in WI. The average RCs in simulated $\mathrm{PM}_{10}$ in different regions was 2.3$5.7 \%$. WI and BTH had the smallest and largest average RCs, respectively. Furthermore, meteorological effects usually exerted positive effects on the changes in $\mathrm{PM}_{10}$ concentrations relative to the year 2012. By contrast, YRD experienced the most adverse meteorological conditions compared with those in 2012. Notably, for all regions, during the period after 2012, RCs caused by anthropogenic emissions decreased drastically. These findings indicate a considerable improvement in air quality after 2013, which is mainly attributable to the reduction in anthropogenic emissions because of efforts such as the APPCAP.

To quantify the relative effects of meteorological and anthropogenic factors in each year, the ratio of meteorological contribution $\left(R_{M}\right)$ was defined as Eq. (2): 

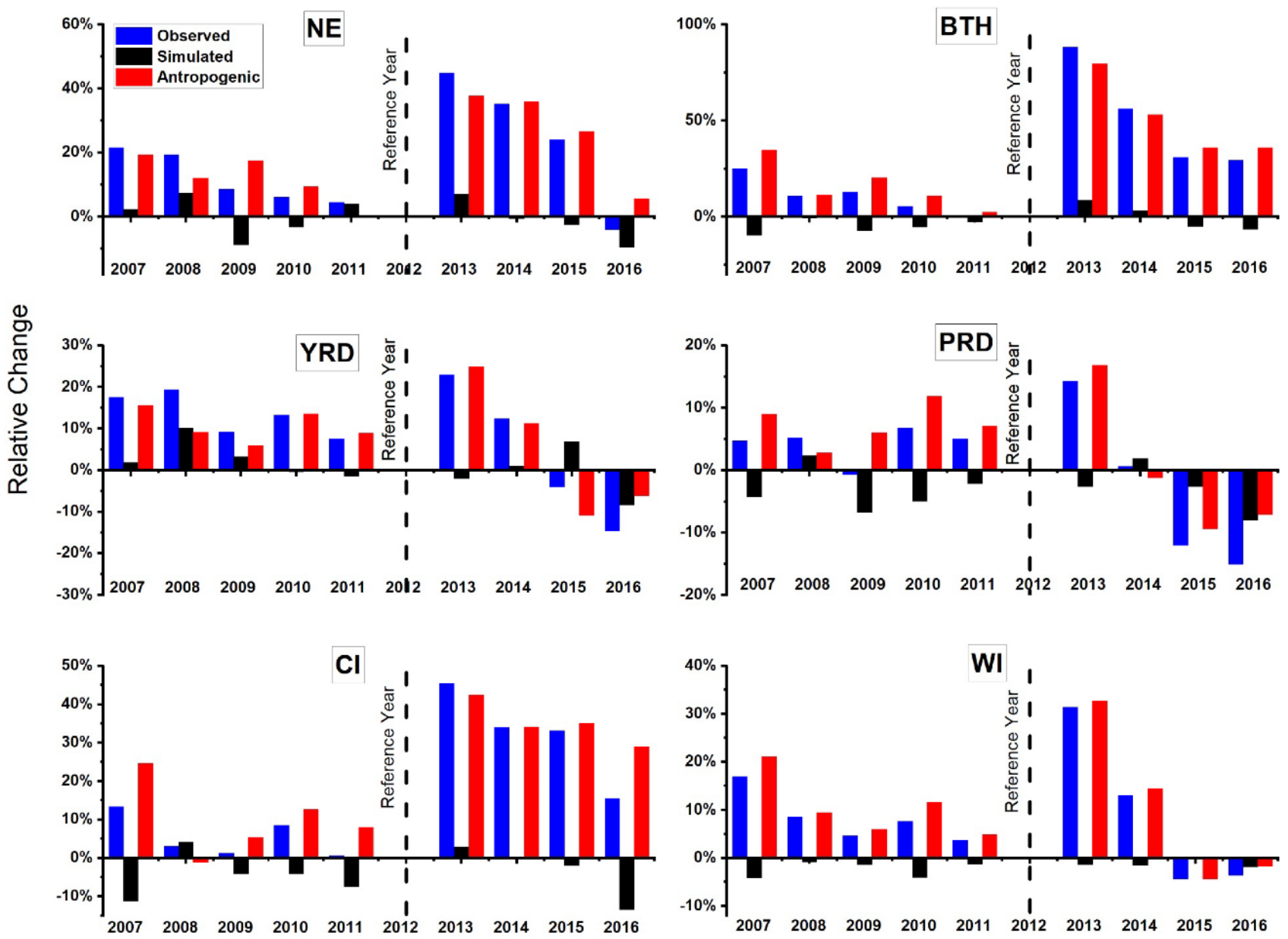

Fig. 6. RCs in the observed (blue bars) and simulated (black bars) $\mathrm{PM}_{10}$, and their difference (anthropogenic effects; red bars) in selected regions.

$$
R_{M}=\frac{\left|R C_{\text {sim }}\right|}{\left|R C_{\text {sim }}\right|+\left|R C_{\text {obs }}-R C_{\text {sim }}\right|} \times 100 \%
$$

where $R C_{\text {sim }}$ and $R C_{\text {obs }}$ represent the simulated and observed $\mathrm{RCs}$, respectively. Next, the ratio of anthropogenic contribution $R_{A}$ was $1-R_{M}$. For the reference year 2012 , because the simulated and observed RCs were equal, both $R_{M}$ and $R_{A}$ become meaningless; hence, they are not discussed here.

Fig. 7 shows the relative contributions of anthropogenic and meteorological factors to the RCs in $\mathrm{PM}_{10}$ for 2007-2016 in different regions using 2012 as reference (i.e., observed $\mathrm{RCs}$ ). The averaged ratios of anthropogenic and meteorological contributions for $\mathrm{PM}_{10}$ during the entire period (2007-2016), the period before 2012 (2007-2011), and the period after 2012 (2013-2016) are summarized in Table 2.

From Fig. 7 and Table 2, for each region, it is evident that anthropogenic effects dominated the changes in $\mathrm{PM}_{10}$ concentration in most of the years. The average anthropogenic ratios reached $70 \%$ for all six regions during the entire period. However, the ratios varied significantly with region and year. In most of the regions (in particular, NE, BTH, PRD, and CI), the anthropogenic ratios before 2012 were less than those after 2012, indicating that the role of anthropogenic emissions gained importance in recent years.

\section{CONCLUSION AND DISCUSSION}

The meteorological effects on the variations in air quality across eastern China during the period of 2007-2016 were examined using WRF and CAMx simulations with a fixed emission inventory. In addition, the relative contributions of meteorological conditions and anthropogenic emissions to the $\mathrm{RCs}$ in $\mathrm{PM}_{10}$ concentrations were determined by comparing the differences between the simulated results and the observations.

The influence of meteorological conditions on changes in air quality varies remarkably by region and time, and the differences in annual AQI (relative to the value of the reference year, 2012) may be as large as $10 \%$. For the entire period of 2007-2016, the linear trends of the meteorological effects were favorable in NE, YRD, and PRD but unfavorable in BTH, WI, and CI. However, these effects differed during specific periods. In particular, the meteorological effects were negative in the period of 2011-2013 but positive in the period of 2014-2016, and they usually displayed greater effects during winter for the majority of the studied regions. 
NE

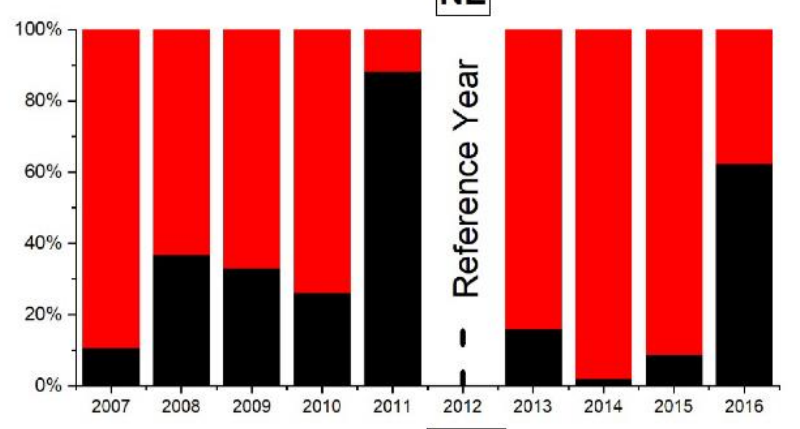

YRD

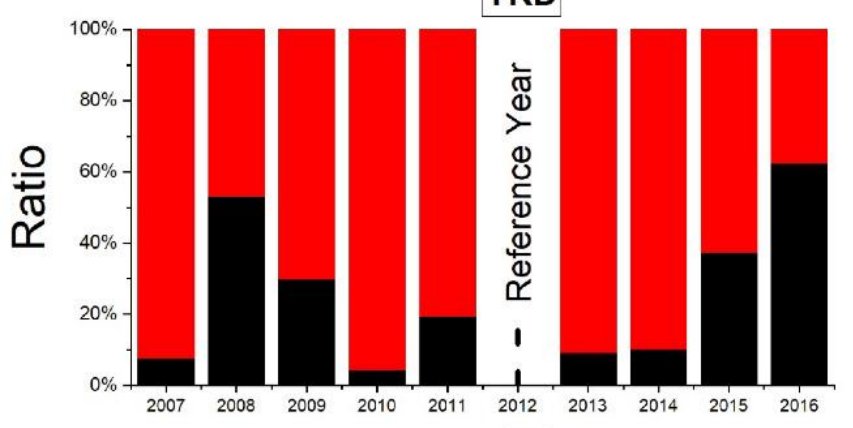

Cl

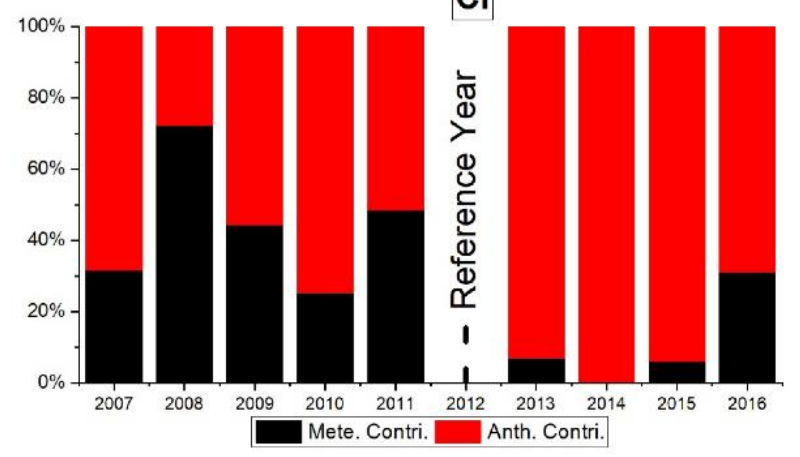

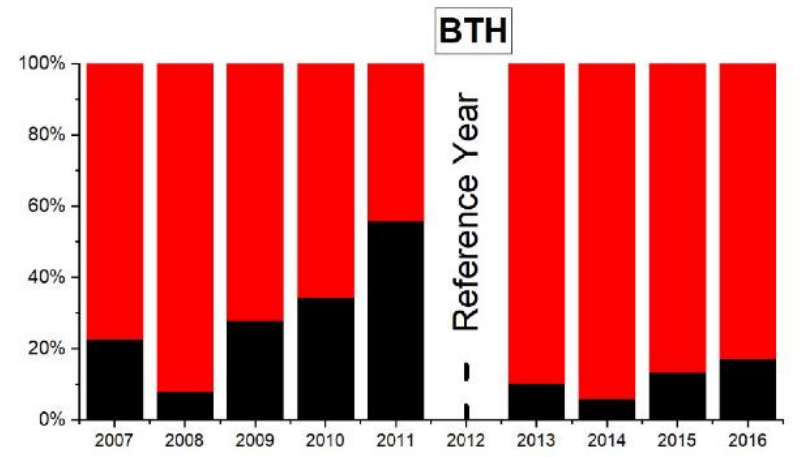

PRD

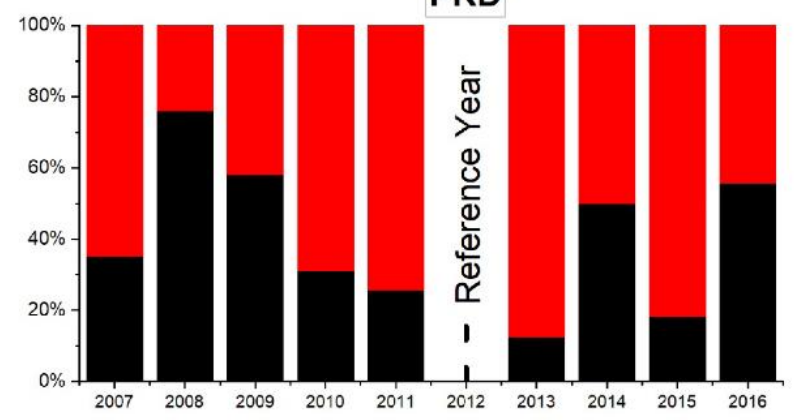

WI

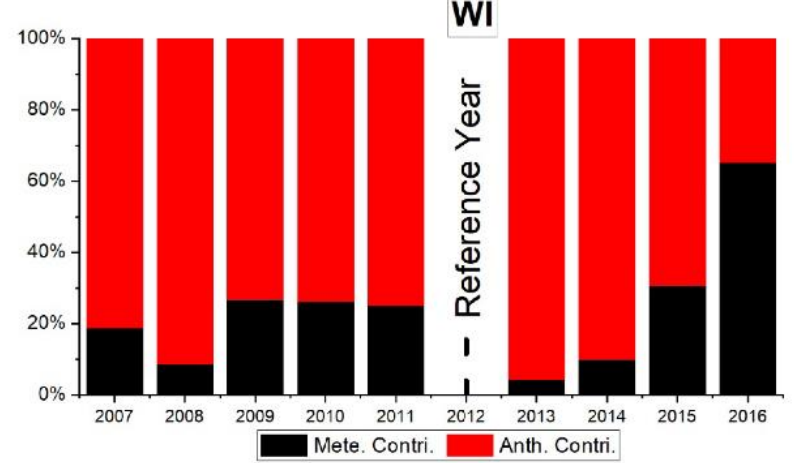

Fig. 7. Ratios of meteorological (black bars) and anthropogenic (red bars) contributions to the RCs in $\mathrm{PM}_{10}$ concentrations in selected regions.

Table 2. Ratios (\%) of anthropogenic and meteorological (ant/met) contributions to RCs in $\mathrm{PM}_{10}$ concentrations in different regions.

\begin{tabular}{lllllll}
\hline Period & NE (ant/met) & BTH (ant/met) & YRD (ant/met) & PRD (ant/met) & CI (ant/met) & WI (ant/met) \\
\hline Whole (2007-2016) & $68.4 / 31.6$ & $78.2 / 21.8$ & $74.0 / 26.0$ & $59.8 / 40.2$ & $70.5 / 29.5$ & $76.1 / 23.9$ \\
Before 2012 (2007-2011) & $60.9 / 29.1$ & $70.2 / 29.8$ & $77.1 / 22.9$ & $54.8 / 45.2$ & $55.7 / 44.3$ & $78.9 / 21.1$ \\
After 2012 (2013-2016) & $77.7 / 22.3$ & $88.3 / 11.7$ & $70.2 / 29.8$ & $65.9 / 34.1$ & $88.9 / 11.1$ & $72.5 / 27.5$ \\
\hline
\end{tabular}

Furthermore, winter meteorological effects tended to deteriorate the air quality in YRD and PRD but improve it in the other regions.

In general, from 2007 to 2016, anthropogenic emissions drove the changes in $\mathrm{PM}_{10}$ concentrations in most of the regions, with the overall average contribution estimated to be $70 \%$. However, the ratios varied significantly by region and year. Most of the regions (NE, BTH, PRD, and CI) exhibited lower anthropogenic ratios before 2012, indicating that the role of anthropogenic emissions on the whole increased after this year. Notably, the relatively small and stable meteorological effects as well as the obviously decreased anthropogenic effects in the majority of the regions after 2012 suggest that reduced anthropogenic emissions were primarily responsible for the considerable improvement in air quality in these regions.

This study presents clear evidence that the variations in air quality in eastern China were mainly caused by anthropogenic emissions; thus, the significant improvements in air quality achieved after 2012 are largely due to the reduction of these emissions, especially in the BTH region, which confirms the success of the air pollution control efforts that have been initiated since 2013, such as the APPCAP. However, it should be noted that meteorological 
conditions may have played a crucial role in certain regions and years, suggesting that severe pollution episodes may occur despite the implementation of intense emission reduction plans. Hence, air pollution forecasting and appropriate emergency measures are critical.

Finally, this study was subject to some limitations, including the uncertainty and relatively low resolution of the emission inventory. Biogenic emissions were also neglected, although their effects on most regular pollutants may be relatively small, particularly in urban areas. Moreover, the complicated nonlinear character of the environmental system may have caused uncertainty in our results. In addition, we focused mainly on $\mathrm{PM}_{10}$ concentrations instead of $\mathrm{PM}_{2.5}$ concentrations because observations of the latter prior to 2013 are unavailable. In the future, the effects of both anthropogenic and meteorological factors, which may vary considerably for different types of pollutants, should be examined.

\section{ACKNOWLEDGMENTS}

The WRF model was obtained from NCAR. The CAMx model was obtained from Ramboll ENVIRON. The authors thank the aforementioned agencies and companies for providing the models and data. This research was supported by the National Key Research and Development Program of China (2016YFC0208504).

\section{REFERENCES}

Buchholz, S., Junk, J., Krein, A., Heinmann, G. and Hoffmann, L. (2010). Air pollution characteristics associated with mesoscale atmospheric patterns in northwest continental Europe. Atmos. Environ. 44: 51835190. https://doi.org/10.1016/j.atmosenv.2010.08.053

Chen, Z.H., Cheng, S.Y., Li, J.B., Guo, X.R., Wang, W.H. and Chen, D.S. (2008). Relationship between atmospheric pollution processes and synoptic pressure patterns in northern China. Atmos. Environ. 42: 60786087. https://doi.org/10.1016/j.atmosenv.2008.03.043

Flocas, H., Kelessis, A., Helmis, C., Petrakakis, M., Zoumakis, M. and Pappas, K. (2009). Synoptic and local scale atmospheric circulation associated with air pollution episodes in an urban Mediterranean area. Theor. Appl. Climatol. 95: 265-277. https://doi.org/10.1007/s00 704-008-0005-9

Fu, C., Jiang, Z., Guan, Z., He, J. and Xu, Z. (2008). Regional climate studies of China. Springer Berlin Heidelberg.

Goncalves, M., Jimenez-Guerrero, P. and Baldasano, J.M. (2009). Contribution of atmospheric processes affecting the dynamics of air pollution in South-Western Europe during a typical summertime photochemical episode. Atmos. Chem. Phys. 9: 849-864. https://doi.org/10.5194/ acp-9-849-2009

Hou, P. and Wu, S. (2016). Long-term changes in extreme air pollution meteorology and the implications for air quality. Sci. Rep. 6: 23792. https://doi.org/10.1038/srep23792

Huang, R.H., Chen, J.L. and Lin, Z.D. (2012).
Characteristics, processes, and causes of the spatiotemporal variabilities of the East Asian monsoon system. Adv. Atmos. Sci. 29: 910-942. https://doi.org/10.1007/s0 0376-012-2015-X

Jacob, D.J. and Winner, D.A. (2009). Effect of climate change on air quality. Atmos. Environ. 43: 51-63. https://doi.org/10.1016/j.atmosenv.2008.09.051

Jeong, J.I. and Park, R.J. (2013). Effects of the meteorological variability on regional air quality in East Asia. Atmos. Environ. 69: 46-55. https://doi.org/10.1016/ j.atmosenv.2012.11.061

Jiang, J., Aksoyoglu, S., El-Haddad, I., Ciarelli, G., Denier van der Gon, H.A.C., Canonaco, F., Gilardoni, S., Paglione, M., Minguillón, M.C., Favez, O., Zhang, Y., Marchand, N., Hao, L., Virtanen, A., Florou, K., O’Dowd, C., Ovadnevaite, J., Baltensperger, U. and Prévôt, A.S.H. (2019). Sources of organic aerosols in Europe: A modeling study using CAMx with modified volatility basis set scheme. Atmos. Chem. Phys. 19: 15247-15270. https://doi.org/10.5194/acp-19-15247-2019

Ji, D.S., Li, L., Wang, Y., Zhang, J.K., Cheng, M.T., Sun, Y., Liu, Z.R., Wang, L.L., Tang G.Q., Hu, B., Chao, N., Wen, T.X. and Miao, H.Y. (2014). The heaviest particulate air-pollution episodes occurred in northern China in January, 2013: Insights gained from observation. Atmos. Environ. 92: 546-556. http://dx.doi.org/10.1016/j.atmose nv.2014.04.048

Li, M., Zhang, Q., Streets, D.G., He, K.B., Cheng, Y.F., Emmons, L.K., Huo, H., Kang, S.C., Lu, Z., Shao, M., Su, H., Yu, X. and Zhang, Y. (2014). Mapping Asian anthropogenic emissions of non-methane volatile organic compounds to multiple chemical mechanisms. Atmos. Chem. Phys. 14: 5617-5638. https://doi.org/10.5194/acp14-5617-2014

Liu, F., Zhang, Q., Tong, D., Zheng, B., Li, M., Huo, H. and He, K.B. (2015). High-resolution inventory of technologies, activities, and emissions of coal-fired power plants in China from 1990 to 2010. Atmos. Chem. Phys. 15: 13299-13317. https://doi.org/10.5194/acp-1513299-2015

Mao, Y.H., Liao, H., Han, Y.M. and Cao, J.J. (2016). Impacts of meteorological parameters and emissions on decadal and interannual variations of black carbon in China for 1980-2010. J. Geophys. Res. 121: 1822-1843. https://doi.org/10.1002/2015JD024019

$\mathrm{Mu}, \mathrm{Q}$. and Liao, H. (2014). Simulation of the interannual variations of aerosols in China: Role of variations in meteorological parameters. Atmos. Chem. Phys. 14: 9597-9612. https://doi.org/10.5194/acp-14-9597-2014

Ramboll Envrion (2016). CAMx version 6.40 User's Guide. Version 6.40. Ramboll Environ, California. http://www.camx.com/files/camxusersguide_v6-40.pdf

Skamarock, W.C., Klemp, J.B., Dudhia, J., Gill, D.O., Barker, D.M., Duda, M.G., Huang, X.Y., Wang, W. and Powers, J.G. (2008). A Description of the Advanced Research WRF Version 3 (No. NCAR/TN-475+STR). University Corporation for Atmospheric Research, USA. https://doi.org/10.5065/D68S4MVH

Tai, A.P.K., Mickley, L.J. and Jacob, D.J. (2010). 
Correlations between fine particulate matter $\left(\mathrm{PM}_{2.5}\right)$ and meteorological variables in the United States: Implications for the sensitivity of $\mathrm{PM}_{2.5}$ to climate change. Atmos. Environ. 44: 3976-3984. https://doi.org/10.1016/j.atmos env.2010.06.060

Tao, M. H., Chen, L. F., Xiong, X. Z., Zhang, M. G., Ma, P. F., Tao, J. H., and Wang, Z. F. (2014). Formation process of the widespread extreme haze pollution over northern China in January 2013: Implications for regional air quality and climate. Atmos. Environ. 98: 417-425. https://doi.org/10.1016/j.atmosenv.2014.09.026

Wang, P., Guo, H., Hu, J.L., Kota, S.H., Ying, Q. and Zhang, H.L. (2019). Responses of $\mathrm{PM}_{2.5}$ and $\mathrm{O}_{3}$ concentrations to changes of meteorology and emission in China. Sci. Total Environ. 662: 297-306. https://doi.org/10.1016/j.scitotenv. 2019.01.227

Wang, W., Bruyère, C., Duda, M., Dudhia, J., Gill, D., Lin, H.C., Michalakes, J., Rizvi, S. and Zhang, X. (2011). ARW Version 3 Modeling System User's Guide January 2011. Mesoscale and Microscale Meteorology Division and National Center for Atmospheric Research, Boulder, CO, USA.

Yang, S., Wang, Y.S. and Zhang, C.C. (2009). Measurement of the vertical profile of atmospheric $\mathrm{SO}_{2}$ during the heating period in Beijing on days of high air pollution. Atmos. Environ. 43: 468-472. https://doi.org/10.1016/j.at mosenv.2008.09.057

Yang, Y., Liao, H. and Lou, S.J. (2015). Decadal trend and interannual variation of outflow of aerosols from East Asia: Roles of variations in meteorological parameters and emissions. Atmos. Environ. 100: 141-153. https://doi.org/10.1016/j.atmosenv.2014.11.004

Yarwood, G., Rao, S., Yocke, M. and Whitten, G.Z. (2005).
Updates to the Carbon Bond chemical mechanism: CB05. Final Report prepared for U.S. EPA, RT-04-00675. http://www.camx.com/publ/pdfs/CB05_Final_Report_1 20805.pdf

Zhai, S.X., Jacob, D.J., Wang, X., Shen, L., Li, K., Zhang, Y.Z., Gui, K., Zhao, T.L. and Liao, H. (2019). Fine Particulate matter $\left(\mathrm{PM}_{2.5}\right)$ trends in China, 2013-2018: separating contributions from anthropogenic emissions and meteorology. Atmos. Chem. Phys. 19: 11031-11041. https://doi.org/10.5194/acp-19-11031-2019

Zhang, L.X. and Zhou, T.J. (2015). Drought over east Asia: A review. J. Clim. 28: 2275-3399. https://doi.org/10.1175 /JCLI-D-14-00259.1

Zhang, Q., Streets, D.G., Carmichael, G.R., He, K.B., Huo, H., Kannari, A., Klimont, Z., Park, I.S., Reddy, S., Fu, J.S., Chen, D., Duan, L., Lei, Y., Wang, L.T. and Yao, Z.L. (2009). Asian emissions in 2006 for the NASA INTEX-B mission. Atmos. Chem. Phys. 9: 5131-5153. https://doi.org/10.5194/acp-9-5131-2009

Zhang, Q. and Crooks, R. (2014). Toward an Environmentally Sustainable Future: Country Environmental Analysis of the People's Republic of China. Asian Development Bank, Philippines.

Zheng, B., Huo, H., Zhang, Q., Yao, Z.L., Wang, X.T., Yang, X.F., Liu, H. and He, K.B. (2014). High-resolution mapping of vehicle emissions in China in 2008. Atmos. Chem. Phys. 14: 9787-9805. https://doi.org/10.5194/acp14-9787-2014

Received for review, December 11, 2019

Revised, March 22, 2020

Accepted, March 22, 2020 